\title{
Pengaruh pijat oksitosin terhadap involusio uterus pada ibu post partum di Puskesmas Totoli Majene
}

\author{
Immawanti ${ }^{1}$, Burhanuddin', \\ Stikes Marendeng Majene \\ Email : $\underline{\text { immawanti.ch@gmail.com }}$
}

\begin{abstract}
Abstrak
Penurunan AKI merupakan salah satu prioritas kebijakan pembangunan kesehatan. Fokus pelayanan di tingkat masyarakat adalah dengan upaya pencegahan termasuk pelayanan keluarga berencana, pelayanan persalinan yang aman serta upaya pencegahan terjadinya perdarahan post partum. Kasus kematian ibu nifas salah satunya akibat akibat perdarahan yang disebabkan oleh involusi uterus yang abnormal/subinvolusi uterus. Subinvolusi uterus menyebabkan kontraksi uterus menurun sehingga perdarahan terjadi terus menerus. Upaya untuk mencegah terjadinya perdarahan post partum adalah dengan memperbaiki kontraksi uterus melalui pemijatan oksitosin maupun pemberian oksitosin. Pijat oksitosin adalah pemijatan di sepanjang tulang belakang sampai costa kelima -keenam dan merupakan suatu tindakan mempercepat kerja saraf parasimpatis untuk menyampaikan perintah ke otak bagian belakang agar oksitosin keluar. Sampel terdiri dari 20 orang. Pengumpulan data dilakukan dengan menilai penurunan involusio kemudian diberikan tindakan pijat oksitosin selanjutnya diadakan penilaian kembali penurunan involusio. Data hasil penelitian dianalisa dengan uji Wilcoxon signed Rank Test, didapatkan nilai $p=0,000<\alpha=0,05$. Kesimpulan dari penelitian ini yaitu ada pengaruh pijat oksitosin terhadap involusio uterus di Puskesmas Totoli Kecamatan Banggae Majene 2018.
\end{abstract}

Kata kunci : Pijat oksitosin, involusio uterus

\begin{abstract}
Decreasing MMR is one of the priorities of health development policy. The focus of services at the community level is prevention efforts including family planning services, safe delivery services and efforts to prevent post partum bleeding. One of the cases of postpartum maternal mortality is due to bleeding caused by abnormal uterine involution / uterine subinvolution. Uterine subinvolution causes contractions of the uterus to decrease so that bleeding occurs continuously. The effort to prevent the occurrence of post partum hemorrhage is to improve uterine contractions through oxytocin massage and oxytocin administration. Massage oxytocin is massage along the spine until the fifth costa - sixth and is an act of accelerating the work of the parasympathetic nerves to convey commands to the back of the brain so that oxytocin exits. The sample consisted of 20 people. Data collection was carried out by assessing the decrease in involution and then being given oxytocin massage action and then reevaluating involuntary reduction. Data from the study were analyzed by the Wilcoxon signed Rank Test, the value of $p=0,000<\alpha=0.05$. The conclusion of this study is that there is an effect of oxytocin massage on uterine involution in Totoli Health Center, Banggae Subdistrict, Majene 2018 .
\end{abstract}

Keywords : Oxytocin massage, Involusio uterus 


\section{Pendahuluan}

Indikator pelayanan kesehatan suatu negara dapat dilihat dari Angka Kematian Ibu (AKI). Salah satu sasaran dalam Visi Indonesia Sehat 2015 (Millenium Development Goal's/MDGs) yaitu menurunkan Angka Kematian Bayi (AKB) dan Angka Kematian Ibu (AKI). Berakhirnya MDGs pada tahun 2015 masih menyisakan sejumlah pekerjaan yang harus diselesaikan pada periode pembangunan berkelanjutan SDGs (Suistanable Development Goal's) yang akan dilaksanakan sampai dengan tahun 2030 (Badan Pusat Statistik, 2016).

AKI di Sulawesi Barat pada tahun 2014 sebanyak 42 kasus, dan pada tahun 2015 mengalami peningkatan menjadi 52 kasus. Kasus kematian ibu paling banyak terjadi pada persalinan yaitu 29 kasus, masa nifas 14 kasus, dan masa kehamilan 9 kasus. Penyebab utama kematian ibu disebabkan karena perdarahan, dapat terjadi saat persalinan maupun periode post partum. Perdarahan pada saat persalinan menunjukkan manajemen proses persalinan tahap ketiga kurang baik (Dinkes Propinsi Sulawesi Barat, 2016).

Upaya pencegahan perdarahan post partum dapat dilakukan semenjak persalinan kala III dan IV dengan pemberian oksitosin. Setelah terjadi pengeluaran plasenta akan terjadi kontraksi dan retraksi uterus yang kuat dan terus menerus untuk mencegah perdarahan post partum. Pada fase kala III kadar oksitosin di dalam plasma meningkat dimana hormon oksitosin ini sangat berperan dalam proses involusio uterus. Involusio uterus atau pengerutan uterus merupakan suatu proses dimana uterus kembali ke kondisi sebelum hamil dengan berat sekitar 60 gram (Cunningham, 2010).

Hasil penelitian yang dilakukan oleh Dasuki dan Rumekti (2008) tentang penatalaksanaan perdarahan post partum pada persalinan lama didapatkan hasil bahwa upaya untuk mencegah terjadinya perdarahan post partum adalah dengan memperbaiki kontraksi uterus melalui pemijatan oksitosin maupun pemberian oksitosin.

Pijat oksitosin adalah pemijatan pada sepanjang tulang belakang (vertebra) dan merupakan usaha untuk merangsang hormon oksitosin setelah melahirkan (Mardiyaningsih, 2010).

Hasil studi pendahuluan yang dilakukan di ruang bersalin Puskesmas Totoli Majene, belum pernah dilakukan penelitian tentang bagaimana pengaruh pijat oksitosin terhadap peningkatan produksi ASI dan pengaruh terhadap involusio uterus. Hasil wawancara dengan salah seorang bidan di ruang bersalin mengatakan belum pernah memberikan tindakan pijat oksitosin kepada ibu post partum normal untuk merangsang kontraksi uterus maupun mengatasi perdarahan. Tindakan yang diberikan selama ini untuk merangsang kontraksi uterus pada pasien post partum adalah dengan tindakan farmakologik dalam bentuk pemberian oksitosin intramuskular pada manajemen aktif kala III serta melakukan massase uterus pada fase kala IV. Jumlah persalinan di Puskesmas Totoli Kecamatan Banggae Majene dari tahun ke tahun mengalami peningkatan, dirataratakan dalam sebulan terdapat 36-43 persalinan.

Berdasarkan latar belakang di atas maka penulis tertarik untuk melakukan penelitian tentang " Pengaruh Pijat Oksitosin Terhadap Involusio Uterus pada Ibu Post Partum di Puskesmas Totoli Kecamatan Banggae Majene 2018".

\section{Metode}

Penelitian ini merupakan penelitian Pre Experimental Design dengan rancangan One Group Pretest-Posttest Design dengan jumlah sampel 20 orang. Populasi dalam penelitian 
ini adalah semua ibu post partum di Puskesmas Totoli Kecamatan Banggae yang memenuhi kriteria inklusi yaitu ibu post partum yang tidak mengalami komplikasi post partum dengan kesadaran baik dan komunikatif.

\section{Hasil}

\section{Tabel 1}

Distribusi Responden Berdasarkan Karakteristik Responden di Puskesmas Totoli Kecamatan Banggae Majene

Tahun 2018

\begin{tabular}{lcc}
\hline \multicolumn{1}{c}{ Karakteristik Responden } & (n) & $\mathbf{( \% )}$ \\
\hline Umur & & \\
19-26 Tahun & 7 & 35.0 \\
27-34 Tahun & 10 & 50.0 \\
35-42 Tahun & 3 & 15.0 \\
Pekerjaan & & \\
IRT & 17 & 85.0 \\
Honorer & 3 & 15.0 \\
Paritas & & \\
Primipara & 4 & 20.0 \\
Multipara & 16 & 80.0 \\
\hline
\end{tabular}

Tabel 2

Analisa Pengaruh Pijat Oksitosin Terhadap Involusio Uterus Pada Ibu Post Partum Hari Pertama, Kedua dan Ketiga di Puskesmas Totoli Kecamatan Banggae

Majene Tahun 2018

\begin{tabular}{|c|c|c|c|c|c|c|c|c|c|}
\hline \multirow[t]{2}{*}{ Variabel } & \multirow[t]{2}{*}{$\mathbf{n}$} & \multirow[t]{2}{*}{ Mean } & \multirow[t]{2}{*}{ Med } & \multirow[t]{2}{*}{$\begin{array}{c}\text { Standar } \\
\text { Devisi }\end{array}$} & \multicolumn{2}{|c|}{$\begin{array}{l}\text { 95\% Confidence } \\
\text { Interval }\end{array}$} & \multirow[t]{2}{*}{ Min } & \multirow[t]{2}{*}{ Max } & \multirow[t]{2}{*}{$\mathbf{P}$} \\
\hline & & & & & Lower & Upper & & & \\
\hline TPU H1 Pre & 20 & 1.15 & 1.00 & 0.366 & 0.98 & 1.32 & 1 & 2 & 0.000 \\
\hline TPU H1 Post & 20 & 1.95 & 2.00 & 0.224 & 1.85 & 2.05 & 1 & 2 & \\
\hline TPU H2 Pre & 20 & 1.05 & 1.00 & 0.224 & 0.95 & 1.15 & 1 & 2 & 0.000 \\
\hline TPU H2 Post & 20 & 1.95 & 2.00 & 0.224 & 1.85 & 2.05 & 1 & 2 & \\
\hline TPU H3 Pre & 20 & 2.30 & 2.00 & 0.470 & 2.08 & 2.52 & 2 & 3 & 0.000 \\
\hline TPU H3 Post & 20 & 2.95 & 3.00 & 0.224 & 2.85 & 3.05 & 2 & 3 & \\
\hline
\end{tabular}




\section{Pembahasan}

Berdasarkan penelitian yang dilakukan distribusi responden berdasarkan umur, responden dengan umur 27-34 tahun lebih banyak yaitu 10 orang atau $(50.0 \%)$ dan responden dengan umur 35-42 tahun yang terendah yaitu sebanyak 3 orang $(15.0 \%)$. Usia muda lebih tinggi daripada usia dewasa. Usia ibu yang relatif muda dimana individu mencapai satu kondisi vitalitas yang prima sehingga kontraksi otot dan kembalinya fungsi kandungan juga semakin cepat karena proses regenerasi dari sel-sel kandungan yang sangat bagus pada usia-usia tersebut (Farrer, 2011). Hasil penelitian dari Liana (2013) menyatakan bahwa usia sangat erat kaitannya dengan penurunan tinggi fundus uteri, semakin tua umur seseorang maka semakin berkurang fungsi reproduksinya yang rata-rata dijumpai pada usia lebih dari 35 tahun dan telah melahirkan lebih dari satu kali (Farrer, 2011).

Responden dengan status IRT yang tertinggi sebanyak 17 orang atau $(85.0 \%)$ dan responden dengan pekerjaan honorer yang terendah sebanyak 3 orang (15.0\%). Dari hasil penelitian ini menunjukkan ibu dengan status pekerjaan sebagai IRT yang terbanyak. Penelitian yang dilakukan oleh Lestari mengatakan bahwa ibu yang tidak bekerja atau sebagai ibu rumah tangga akan sering atau banyak kesempatan untuk mencari informasi, memberikan ASI dan mengasuh bayinya (Lestari, 2011). Ibu tidak memberikan ASI secara eksklusif karena ibu harus bekerja. Tidak diberikannya ASI secara eksklusif juga akan mempengaruhi sekresi dari hormon oksitosin sehingga akan memberikan dampak akan semakin memanjangnya proses involusi uterus.

Responden dengan paritas multipara yang tertinggi sebanyak 16 orang atau $(80.0 \%)$ dan responden dengan paritas primipara yang terendah sebanyak 4 orang (20.0\%).
Berdasarkan hasil penelitian ini diketahui bahwa karakteristik ibu post partum berdasarkan paritas didominasi oleh responden multipara. Paritas merupakan intensitas persalinan atau juga dapat didefenisikan banyaknya kelahiran hidup yang dimiliki seorang ibu, semakin sering wanita melahirkan akan berpengaruh terhadap tonus otot sehingga berpengaruh terhadap proses normalnya involusi uterus dan perdarahan postpartum (Yuliatun, 2017).

\section{Pengaruh Pijat Oksitosin terhadap Involusio Uterus pada Ibu Post Partum}

Perbedaan nilai rata-rata dari pretest dan posttest responden tentang pemberian pijat oksitosin terhadap involusio uterus pada ibu post partum, sebelum diberikan tindakan pijat oksitosin nilai rata-rata hari pertama sebesar 1.15, hari kedua sebesar 1.05 dan hari ketiga sebesar 2.30 sedangkan setelah diberikan pijat oksitosin nilai rata-rata hari pertama sebesar 1.95, hari kedua sebesar 1.95 dan hari ketiga sebesar 2.95 .

Hasil analisa menggunakan uji wilcoxon diperoleh $p$-value hari pertama, kedua dan ketiga sebesar $=0.000$ lebih kecil dari nilai $(\alpha)=0.05$ dengan demikian dapat dikatakan ada pengaruh Pijat Oksitosin Terhadap Involusio Uterus Pada Ibu Post Partum di Puskesmas Totoli Kecamatan Banggae Majene Tahun 2018.

Rata-rata penurunan tinggi fundus uteri (TFU) hari ke 1 (satu) pada ibu postpartum adalah 1-2 $\mathrm{cm}$ di bawah pusat, rata-rata penurunan tinggi fundus uteri (TFU) pada hari ke 2 (dua) adalah 1-2 cm dibawah pusat sedangkan rata-rata penurunan tinggi fundus uteri (TFU) pada hari ke 3 (tiga) adalah 2-3 cm dibawah pusat. Hasil tersebut didapat diartikan bahwa rerata penurunan tinggi fundus uteri (TFU) atau proses pengecilan uterus kembali seperti kondisi sebelum hamil (involusio uteri) 
pada ibu-ibu post partum yang dilakukan pijat oksitosin lebih cepat. Namun ada beberapa ibu potpartum yang tidak mengalami penurunan tinggi fundus uteri (TFU) atau proses pengecilan uterus seperti kondisi sebelum hamil (involusio uteri) karena pada ibu-ibu post partum tersebut tidak mengikuti semua proses pijat oksitosin.

Hal ini sesuai dengan konsep teori yang disampaikan oleh Manuaba (2013) tentang penurunan tinggi fundus uteri pada masa involusi ibu post partum bahwa terjadi penurunan $1 \mathrm{~cm}$ setiap hari postpartum, pada hari ke 6 setelah partus adalah $6 \mathrm{~cm}$ dibawah pusat, pada hari ke 8 setelah partus adalah $8 \mathrm{~cm}$ dibawah pusat dan pada hari ke 10 setelah partus, tinggi fundus uteri tidak teraba. Hal senada disampaikan oleh Wiknjosastro bahwa "uterus secara berangsur-angsur menjadi kecil (involusi) sehingga akhirnya kembali seperti sebelum hamil. Pembuluhpembuluh darah yang berada diantara anyaman otot-otot uterus akan terjepit. Proses ini akan menghentikan perdarahan setelah plasenta dilahirkan".

Efek fisiologis dari pijat oksitosin ini adalah merangsang kontraksi otot polos uterus baik pada proses saat persalinan maupun setelah persalinan sehingga bisa mempercepat proses involusi uterus (Indiarti 2009). Penelitian ini diperkuat dengan teori yang diungkapkan oleh Pillitery bahwa pijat oksitosin dapat merangsang hipofisis anterior dan posterior untuk mengeluarkan hormon oksitosin (Dahlan \& Sopiyudin, 2012).

Teori diatas sejalan dengan penelitian ini dimana adanya kontraksi uterus yang kuat sebagai akibat dari intervensi peneliti berupa pijatan oksitosin yang menyebabkan penurunan tinggi fundus uterus pada responden dengan gambaran hasil penelitian pada responden yang dipijat oksitosin mengalami penurunan yang lebih cepat, sesuai dengan teori yaitu tinggi fundus uterus menurun $1 \mathrm{~cm}$ dibawah pusat tiap hari pasca melahirkan (Manuaba, 2012). Secara berangsur-angsur menjadi kecil (involusi) hingga akhirnya kembali seperti sebelum hamil. Pemberian pijat oksitosin kepada responden bertujuan untuk mengetahui penurunan involusi uterus. Hal ini didukung oleh penelitian yang dilakukan oleh Khairani L, Komariah M, \& Mardiah W (2014) menyatakan bahwa pemberian pijat oksitosin berpengaruh terhadap involusi uterus pada ibu post partum dengan nilai $\mathrm{p}=0.01$ nilai tersebut $<0.05$ ada pengaruh antara pijat oksitosin terhadap involusi utertus (Khairani, 2012).

Pemberian pijat oksitosin merupakan salah satu cara untuk mempercepat penurunan involusi uterus. Menurut para ahli penurunan involusi uterus lebih cepat karena responden dan keluarga responden diajak memanfaatkan alat indra untuk memahami materi yang disampaikan. Penurunan involusi uterus yang cepat terjadi karena intervensi pijat oksitosin yang diajarkan dengan cara ceramah dan tanya jawab serta di berikan leaflet tentang cara pijat oksitosin yang benar untuk dibaca sehingga responden dan keluarga responden yang melakukan pijat oksitosin dapat lebih mengerti dan mengingat apa yang telah di ajari oleh peneliti. Penelitian ini didukung oleh Futri (2010) yaitu metode ceramah dan tanya jawab serta responden dapat bertanya dengan pemateri secara langsung sehingga responden dapat lebih memahami apa yang disampaikan pemateri dan meningkatkan pengetahuan responden.

Hasil penelitian yang sejalan juga dilakukan oleh Hamranani yang menyimpulkan bahwa oksitosin digunakan untuk memperbaiki kontraksi uterus setelah melahirkan sebagai salah satu tindakan untuk mencegah terjadinya perdarahan (Hamranani, 2010). 
Berdasarkan hasil penelitian tersebut dan hasil penelitian yang dilakukan peneliti dapat di simpulkan bahwa pemberian pijat oksitosin merupakan salah satu cara yang efektif untuk pempercepat involusi uterus.

\section{Kesimpulan}

Pada penelitian ini diperoleh kesimpulan bahwa ada pengaruh pijat oksitosin terhadap involusio uterus pada ibu post partum di Puskesmas Totoli Kecamatan Banggae Majene Tahun 2018.

\section{Saran}

1. Bagi Institusi Pelayanan (Puskesmas) Diharapkan pijat oksitosin dijadikan sebagai protap di Puskesmas dan Puskesmas dapat menjalankan fungsi sebagai edukator dengan mengajarkan dan mensosialisasikan kepada keluarga dan pasien tentang manfaat pijat oksitosin.

2. Bagi Instansi Pendidikan

Diharapkan agar setiap mahasiswanya yang praktek di lapangan khususnya maternitas, mampu menerapkan/ melaksanakan pijat oksitosin pada ibu post partum dan institusi pendidikan dapat menyusun program serta mengembangkan kurikulum pendidikan keperawatan dalam memperkuat teori keperawatan khususnya tentang tindakan pijat oksitosin.

3. Bagi Peneliti Selanjutnya

Disarankan untuk mengembangkan penelitian ini dengan jumlah responden yang lebih banyak dan membuat kelompok perlakuan dan kelompok kontrol.

4. Bagi Responden/Keluarga Responden

Diharapkan bagi responden/keluarga responden untuk dapat menerapkan pijat oksitosin agar mempercepat involusio uterus.

\section{Daftar Pustaka}

Alimul, A. (2011). Riset Keperawatan dan Teknik Penulisan Ilmiah. Jakarta: Salemba Medika.

Ambarwati, E.A., \& Wulandari D. (2010). Asuhan Kebidanan Masa Nifas. Yogyakarta: Mitra Cendekia.

Anggraini, Y. (2010). Asuhan Kebidanan Masa Nifas. Yogyakarta: Pustaka Rihama.

Badan Pusat Statistik. (2016). Potret Awal Tujuan Pembangunan Berkelanjutan (Suistanable Development Goals). Jakarta: Statistics Indonesia.

Bahiyatun. (2013). Asuhan Kebidanan Nifas Normal. Jakarta: EGC.

Bobak., Lowdermilk., \& Jensen. (2005). Buku Ajar Keperawatan Maternitas. Jakarta: EGC.

Cunningham. (2010). Obstetri Williams. Jakarta: EGC.

Dasuki., Rumekti (2008). Perbandingan Efektifitas Misoprostol Peroral dan Oksitosin untuk Prevensi Perdarahan Post Partum. 7 April 2018. http://chnrl.net.publikasi.pdf.MPO.

Departemen Kesehatan RI. (2007). Pelatihan Konseling Menyusui. Jakarta.

Dinas Kesehatan Propinsi Sulawesi Barat. (2016). Profil Kesehatan Sulawesi Barat 2015. Mamuju.

Dinas Kesehatan Propinsi Sulawesi Barat. (2016). Profil Kesehatan Sulawesi Barat 2015. Mamuju.

Johnson, J. (2010). Keperawatan Maternitas. Yogyakarta: Rapha Publishing.

Jordan, S. (2014). Farmakologi Kebidanan. Jakarta: EGC. 
Kementerian Kesehatan RI. (2017). Profil Kesehatan Indonesia Tahun 2016. Jakarta.

Manuaba, Ida Bagus Gede. (2010). Ilmu Kebidanan Penyakit Kandungan dan Keluarga Berencana untuk Pendidikan Bidan. Jakarta: EGC.

Marasinghe., Condous. (2009). Kematian Ibu Tertinggi di Asia. 7 April 2018. http://menegp.go.id.indeks.php.

Mardiyaningsih. (2010). Efektifitas Kombinasi Teknik Marmet Dan Pijat Oksitosin Terhadap Produksi ASI Ibu Post Seksio Sesarea Di Rumah Sakit Wilayah Jawa Tengah. Tesis. Jakarta: Universitas Indonesia.

Margono. (2010). Metodologi Penelitian Pendidikan. Jakarta: Rineka Cipta.

Mochtar, R. (2011). Sinopsis Obstetri. Jakarta: EGC.

Nursalam. (2013). Konsep dan Penerapan Metodologi Penelitian Ilmu Keperawatan (Edisi 3). Jakarta: Salemba Medika.

Oxorn Harry., Forte William. (2010). Ilmu Kebidanan : Patologi dan Fisiologi Persalinan. Yogyakarta: Andi Offset.

Prabowo. (2010). Faktor-faktor yang Mempengaruhi Involusio Uterus . 27 Juli 2018. http://web.Ebschost.

Prawirohardjo, S. (2014). Ilmu Kebidanan. Jakarta: Yayasan Bina Pustaka Sarwono Prawirohardjo.

Purnama. (2013). Efektivitas Antara Pijat Oksitosin dan Breast Care Terhadap Produksi ASI Pada Ibu Post Partum Dengan Sectio Caesarea di RSUD Banyumas. Skripsi. Banyumas: Universitas Jenderal Soedirman.

Reeder, S. (2013). Keperawatan Maternitas, Kesehatan Wanita, Bayi dan Keluarga. Jakarta: EGC.
Roesli, U. (2009). Panduan Praktis Menyusui. Jakarta: Puspa Swara.

Rukiyah, Y., Yulianti, L., Maemunah., \& Susilowati. (2012). Asuhan Kebidanan 1 Kehamilan. Jakarta: Trans Info Media (TIM)

Saleha, S. (2009). Asuhan Kebidanan pada Masa Nifas. Jakarta: Salemba Medika.

Sofia, D. (2015). Pengaruh Pijat Oksitosin Terhadap proses Involusio Uterus. http://www.academia.edu> (01 Juli 2018).

Stanton C., Samuel N., \& Luke CM. (2013). Effect on Post Partum Haemorrahage of Prophylactic Oxytocin 10 IU by Injection by Community Health Officer in Ghana. April 7, 2018. http://www.ncbi.nlm.nih.gov/pmc/artic les/pmc3794862.

Suherni. (2008). Perawatan Masa Nifas. Yogyakarta: Fitramaya.

Varney, H. (2016). Buku Ajar Asuhan Kebidanan (Edisi 4). Jakarta:EGC.

Widuri, H. (2013). Cara Mengelola ASI Eksklusif Bagi Ibu Bekerja. Yogyakarta: Gosyen Publishing.

Widyasih, H., Suherni., \& Rahmawati. (2010). Perawatan Masa Nifas. Jakarta: Fitra Maya.

Wiknjosastro. (2010). Panduan Praktis Pelayanan Kesehatan Maternal dan Neonatal. Jakarta: Bina Pustaka. 